This item was submitted to Loughborough's Research Repository by the author.

Items in Figshare are protected by copyright, with all rights reserved, unless otherwise indicated.

\title{
Modifying conventional microwave antenna designs using fine scale structures and nanomaterials
}

PLEASE CITE THE PUBLISHED VERSION

http://dx.doi.org/10.1109/LAPC.2009.5352428

PUBLISHER

Loughborough University (@ IEEE)

VERSION

AM (Accepted Manuscript)

LICENCE

CC BY-NC-ND 4.0

\section{REPOSITORY RECORD}

Whittow, W.G., and J.C. Vardaxoglou. 2019. "Modifying Conventional Microwave Antenna Designs Using Fine Scale Structures and Nanomaterials". figshare. https://hdl.handle.net/2134/12382. 
This item was submitted to Loughborough's Institutional Repository (https://dspace.lboro.ac.uk/) by the author and is made available under the following Creative Commons Licence conditions.

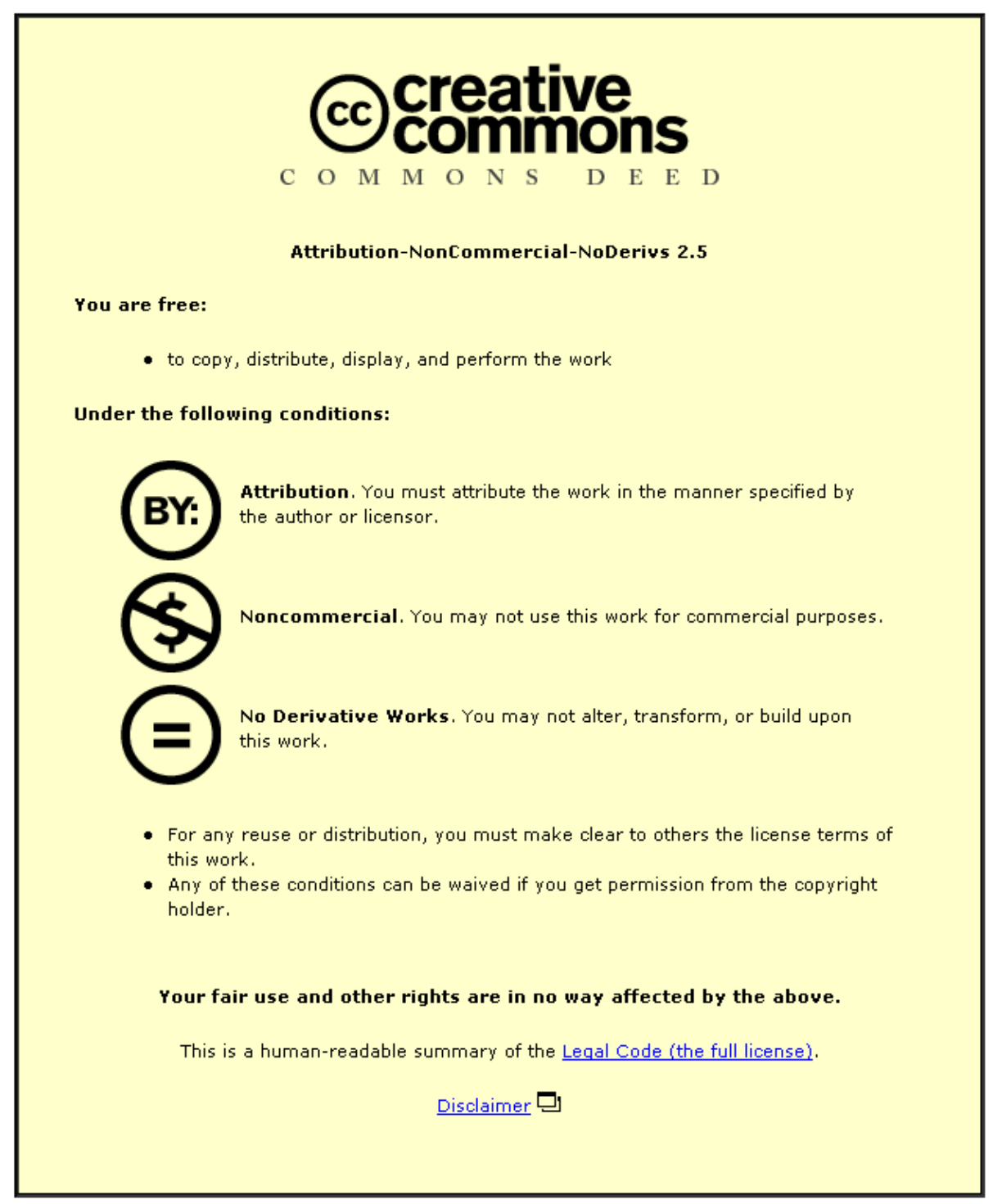

For the full text of this licence, please go to: http://creativecommons.org/licenses/by-nc-nd/2.5/ 


\title{
Modifying Conventional Microwave Antenna Designs Using Fine Scale Structures and Nanomaterials
}

\author{
William Whittow $^{\# 1}, \mathrm{~J}$ (Yiannis) Vardaxoglou ${ }^{\# 2}$ \\ ${ }^{\#}$ Electronic and Electrical Engineering Department, Loughborough University, Loughborough, LE11 $3 T U$, UK \\ ${ }^{1}$ w.g.whittow@lboro.ac.uk, ${ }^{2}$ j.c.vardaxoglou@lboro.ac.uk
}

\begin{abstract}
This paper investigates the possibility of designing and fabricating microwave antennas using metallic nanomaterials. Specifically, we will consider modifying the structure of conventional designs including dipoles, loops and apertures. FDTD simulations are used to examine these modified structures. Due to the prohibitive computational requirements of modelling nanoscale objects on a millimetre scale, the structures are approximated using larger scale objects. However, cell sizes down to $2 \mu \mathrm{m}$ have been considered. The results show that the frequency can be decreased. However, typically the bandwidth decreases.
\end{abstract}

\section{INTRODUCTION}

Nanoelectromagentics is an exciting new area of research and generally involves very high frequencies. This paper will show that nanomaterials can be applied to much lower frequencies by clustering many such particles together. In a related area, homogeneous ultrathin copper and indium tin oxide layers were used to make microwave antennas that were transparent at optical frequencies [1]. Some exploratory computer simulations by the Investigators at Loughborough have shown that antennas composed of very small conducting metallic dots have very interesting properties, depending on their size and the gaps between them [2][3][4]. Note, that the memory requirements of simulating nanoscale structures over a length or area of several $\mathrm{mm}$ are not currently feasible and simplifications were made.

Metamaterials are one of the most interesting phenomena in electromagnetics, having remarkable properties that are not found in nature [5-7]. They use periodic cellular configurations to create an overall structure where the properties are due to the geometry not the material itself. Therefore, an antenna composed of sub-wavelength nanosized periodic structures, can be thought of as being similar to a metamaterial and it is expected to exhibit interesting behaviour. Mittra [7] has reviewed the area of small antennas and concludes that the key challenges are size reduction, directivity enhancement, bandwidth widening and backlobe suppression and he suggests that new advances in metamaterials may be the answer to improve antenna performance. Caloz [6] has shown that using smaller unit cells of metamaterials can improve the homogeneity and the isotropy, extend the bandwidth, enhance the functionality and reduce refraction and diffraction losses at interfaces with other media.

Constructing antennas using nanomaterials has enormous potential in antenna designs for many different applications in terms of enhanced electromagnetic performance and improved physical performance. In addition, the antenna and substrate can be fabricated simultaneously with novel bespoke properties.

\section{METHODOLOGY AND GEOMETRY}

Empire Finite-difference time-domain (FDTD) software was used in this work (www.empire.de). A vertically polarized Ez, Hy plane wave propagating in the $\mathrm{X}$ direction was created by using an air filled microstrip line (MSL), see Fig 1 (a). This acts as a parallel plate waveguide. The cut off frequency of the cavity, $\mathrm{f}_{\mathrm{c}}=\mathrm{c} / \mathrm{MAX}(\mathrm{W}$ or $\mathrm{H})$ and therefore, at $40 \mathrm{GHz}$, the (maximum) height and width of the waveguide is $7.5 \mathrm{~mm}(7500 \mu \mathrm{m})$. Perfect electric conductors are used at the two sides of the MSL and perfect magnetic conductors are used at the top and bottom boundaries. This means the sample is infinitely periodic in two dimensions. Using an MSL, with a port at either end, is a very memory efficient method of examining the reflection and transmission coefficients of our structures

In this paper three geometries are considered; a dipole, a loop and an aperture antenna. Note all the antennas are passive objects which re-radiate the plane wave excitation. They were simulated as silver as this is the material that we intend to make our samples from.

The dipole was $6500 \mu \mathrm{m}$ long and $10 \mu \mathrm{m}$ thick. $10 \mu \mathrm{m}$ high, horizontal strips, that varied in length from 30 to $530 \mu \mathrm{m}$, were added along the length of the dipole (Fig. 1 (b)).

The passive loop radiator has exterior dimensions of $6500 \mu \mathrm{m}$ (Fig. 1 (a)) and was $10 \mu \mathrm{m}$ thick, $10 \mu \mathrm{m}$ wide vertical strips were added along both the top and bottom section of the loop (Fig. 1 (c)). The height of these strips was varied from 30 to $330 \mu \mathrm{m}$ 
The third type of antenna considered was an aperture. This was created by adding a $10 \mu \mathrm{m}$ thick silver sheet at the centre of the microstrip line that extended to the edge of the line in the $\mathrm{Y}$ and $\mathrm{Z}$ directions. A horizontal aperture was cut into the middle of this sheet which was $5500 \mu \mathrm{m}$ wide and $100 \mu \mathrm{m}$ high. 10 and $20 \mu \mathrm{m}$ metallic dots were then added to the aperture and were uniformly spaced (Fig. 1 (d-f)). Also 10 and $20 \mu \mathrm{m}$ high horizontal strips were added to the aperture (Fig. 1 (g-h)).

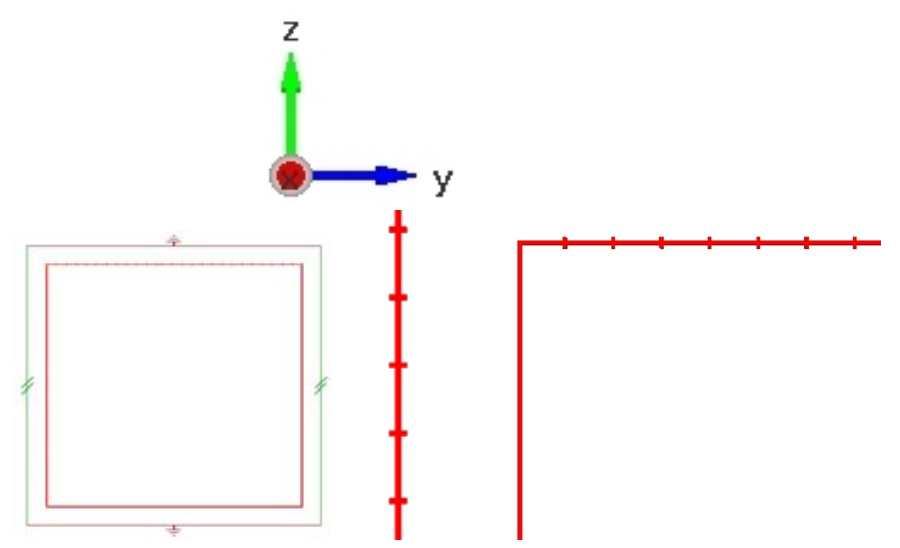

(a)

(b)

(c)

(d)

(e)
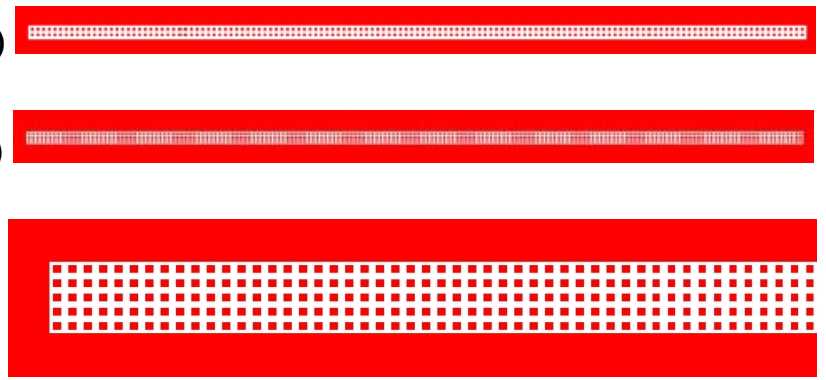

(f)

(g)

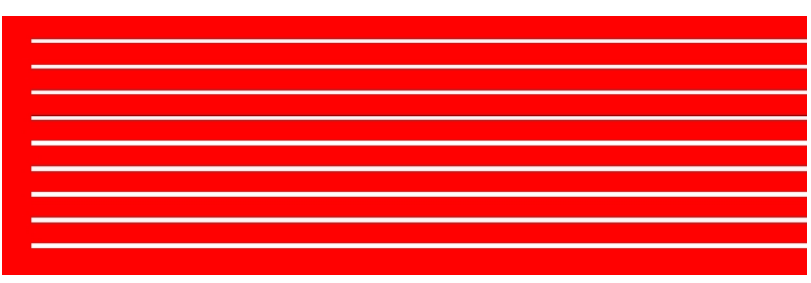

(h)

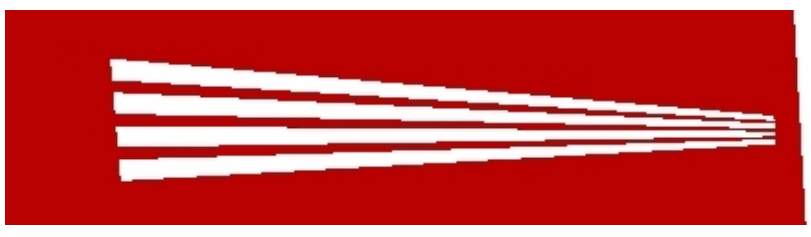

Fig. 1 The geometry considered; a) a $6500 \mu \mathrm{m}$ loop in a $7500 \mu \mathrm{m}$ microstrip line (with perfect magnetic conductors at the sides and perfect electric conductors at the top and bottom, b) a small section of a $10 \mu \mathrm{m}$ thick dipole with $10 \mu \mathrm{m}$ high, $30 \mu \mathrm{m}$ horizontal strips, c) a section of a corner of a loop with $30 \mu \mathrm{m}$ high, $10 \mu \mathrm{m}$ wide vertical strips on the top (and bottom), d) a $5500 \mu \mathrm{m}$ wide, $100 \mu \mathrm{m}$ high aperture with $20 \mu \mathrm{m}$ dots separated by $20 \mu \mathrm{m}$, e) the same aperture with $20 \mu \mathrm{m}$ dots separated by $10 \mu \mathrm{m}$, f) a section of the aperture containing $10 \mu \mathrm{m}$ dots separated by $10 \mu \mathrm{m}$, g) a small section of aperture with eight $10 \mu \mathrm{m}$ high horizontal strips, h) oblique view of three $10 \mu \mathrm{m}$ high horizontal strips in aperture. Note these pictures are not to the same scale.

\section{RESULTS}

The results in this paper show how the transmission coefficients (S21) vary with the addition of fine scale structures. Note that the samples were passive radiators which caused changed to the reflection and transmission coefficients of the microstrip line. The S11 can be found using $S 11^{2}+$ $S 21^{2} \approx 1$ as the losses were negligible.

\section{A. Dipole with Horizontal Strips}

In this section, 50 horizontal metallic strips were added along the length of the dipole. The height and thickness was $10 \mu \mathrm{m}$ and the width was varied from 30 to $530 \mu \mathrm{m}$. The results are shown in Fig. 2. Note that adding significantly more than 50 strips, required a very large number of Yee cells and the simulations took a very long time to run on a desktop computer. This represents an approximation of a structure we intend to build in the future with millions of nanoscale protrusions along the length of the dipole. The addition of fifty $30 \mu \mathrm{m}$ strips increased the bandwidth of the original dipole. As the length of the strips increased, the resonant frequency decreased from 22 to $16.8 \mathrm{GHz}$. In addition, the bandwidth (and therefore the fractional bandwidth) also increased.

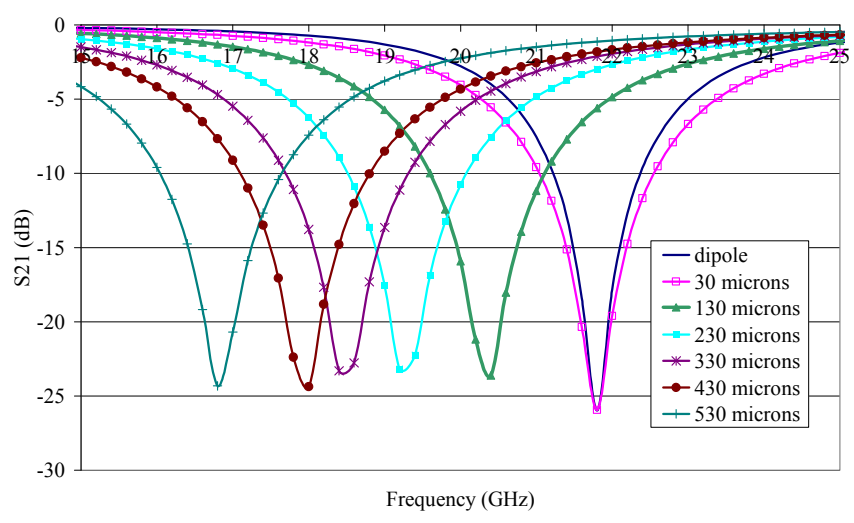

Fig. 2. The transmission coefficient of a dipole with 50 horizontal strips of various lengths.

\section{B. Loop with Vertical Strips}

In this section, 50 vertical metallic strips were added along both the top and bottom sections of a loop (Fig. 1 (a and c). The width and thickness was $10 \mu \mathrm{m}$ and the height was varied from 30 to $330 \mu \mathrm{m}$. The results are shown in Fig. 3. As the length of the strips increased, the resonant frequency decreased and the S21 remained stable. The 10dB bandwidth 
was relatively constant and therefore the fractional bandwidth increased with the length of the vertical strips.

As a comparison, 50 horizontal strips were added to both sides of the loop. With this geometry and the same vertically polarised plane wave excitation, the strips had negligible effect.

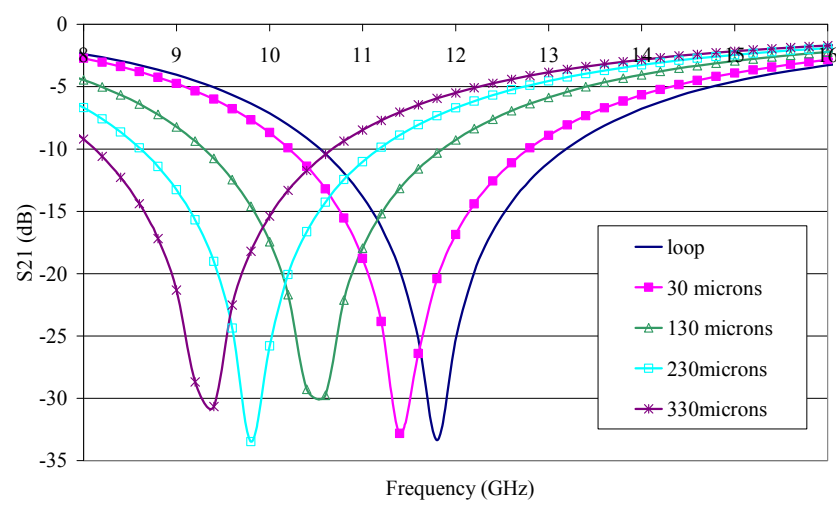

Fig. 3. The transmission coefficient of a loop with 50 vertical strips of various lengths added to both the top and bottom sections of the loop.

\section{Aperture with Metallic Dots}

The horizontal aperture had a pass band at $26.8 \mathrm{GHz}$ where the majority of the power passed from Port 1 to Port 2 of the MSL. This was modified by adding uniformly spaced metallic dots within the aperture Fig. $1(\mathrm{~d}-\mathrm{f})$. In this paper we use the term $d o t$ to refer to a small metallic square object; the dots had the same thickness as the aperture $(10 \mu \mathrm{m}) .10$ and $20 \mu \mathrm{m}$ dots were considered and the spacing between the dots was varied between 2 and $20 \mu \mathrm{m}$. Note that meshing the structure finely in two dimensions is very computationally expensive and hence finer meshes could not be simulated. In future work we will construct these samples using metallic nanoparticles by controlling the density of particles in specific locations.

The results are shown in Fig. 4. As the ratio of metallic dots to gaps in the aperture increased, the resonant frequency decreased. However, the S21 also decreased in magnitude. Therefore, there is a compromise that has to be made between the S21 and the bandwidth and the antenna size. The effects near $40 \mathrm{GHz}$ are directly due to the size of the MSL.

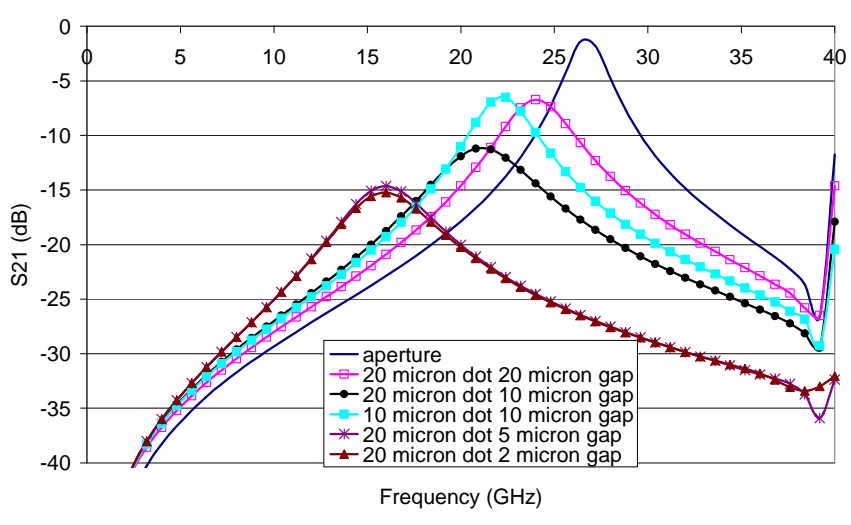

Fig. 4. The transmission coefficient of an aperture containing uniformly distributed 10 and $20 \mu \mathrm{m}$ metallic dots.

Note that the height of the aperture was fixed at $100 \mu \mathrm{m}$ and due to the finite size of the dots, the gap from the edge of the aperture to the top and bottom lines of dots was different from the gap between the dots (Fig. 1 (d-f)). Therefore, there were four $20 \mu \mathrm{m}$ dots along the $\mathrm{Z}$ direction of the aperture with both the 2 and $5 \mu \mathrm{m}$ gaps. This also explains why the $20 \mu \mathrm{m}$ dots with $20 \mu \mathrm{m}$ gaps (two dots vertically), resonated at a higher frequency that the $10 \mu \mathrm{m}$ dots with $10 \mu \mathrm{m}$ gaps (five dots vertically) as there is a higher ratio of metal to non-metal in the aperture with the smaller dots. It is interesting to note that the smaller dots produces a better S21 despite resonating at a lower frequency. These results are summarised in Table 1.

TABLE I. SIZE OF DOTS IN APERTURE

\begin{tabular}{|c|c|c|c|c|r|}
\hline $\begin{array}{c}\text { Dot } \\
(\mu \mathrm{m})\end{array}$ & $\begin{array}{c}\text { Gap } \\
(\mu \mathrm{m})\end{array}$ & $\begin{array}{c}\text { Gap at } \\
\text { top / } \\
\text { bottom } \\
(\mu \mathrm{m})\end{array}$ & $\begin{array}{c}\% \\
\text { Metal } \\
\text { in } \\
\text { aperture }\end{array}$ & $\begin{array}{c}\text { Freq } \\
(\mathrm{GHz})\end{array}$ & $\begin{array}{c}\text { S21 } \\
(\mathrm{dB})\end{array}$ \\
\hline 0 & N/A & N/A & 0 & 26.8 & -1.01 \\
\hline 10 & 10 & 5 & 25.0 & 22.4 & -6.38 \\
\hline 10 & 20 & 15 & 9.9 & 24.5 & -4.4 \\
\hline 10 & 40 & 20 & 4 & 25.4 & -3.1 \\
\hline 20 & 20 & 20 & 19.9 & 24.2 & -6.74 \\
\hline 20 & 10 & 10 & 39.9 & 21.2 & -11.06 \\
\hline 20 & 5 & 2.5 & 64.0 & 16.2 & -14.42 \\
\hline 20 & 2 & 8 & 72.7 & 16.0 & -15.39 \\
\hline 40 & 10 & 5 & 64 & 17.2 & -18.6 \\
\hline
\end{tabular}

\section{Aperture with Horizontal Metal Strips}

As a variation of adding dots in the aperture, $10 \mu \mathrm{m}$ high horizontal strips were also added to the aperture (Fig. $1 \mathrm{~g}-\mathrm{h}$ ). Fig. 5, shows the effect on the S21 of adding up to nine strips. As the number of strips was increased, the resonant frequency decreased. The S21 also decreased in magnitude. One to four $20 \mu \mathrm{m}$ high horizontal strips were also considered; the frequency was decreased but the S21 was worse than with the $10 \mu \mathrm{m}$ strips 


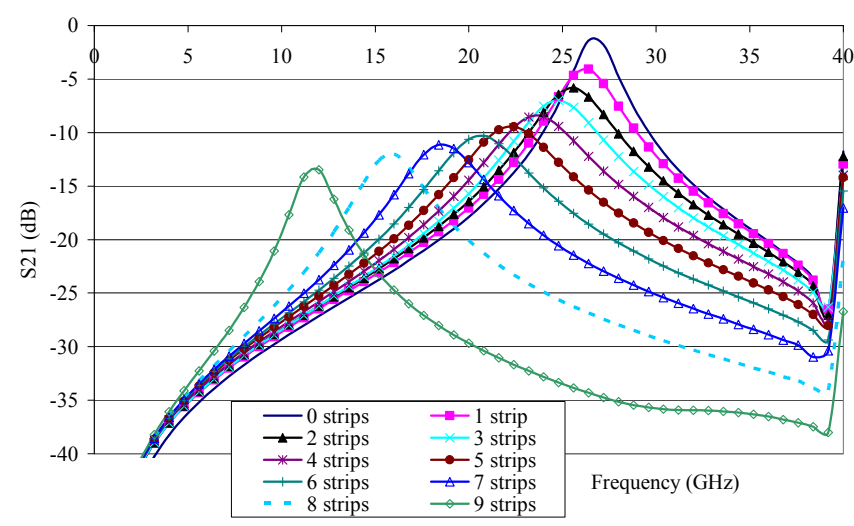

Fig. 5. The transmission coefficient of an aperture containing $10 \mu \mathrm{m}$ high horizontal strips.

\section{E. Analysis of Aperture Results}

The results in sections $\mathrm{C}$ and $\mathrm{D}$ showed that the resonant frequency of the aperture could be decreased at the expense of the magnitude of the S21. The frequency results are plotted against the S21 in Fig. 6. The ideal antenna that is both small in size and an effective radiator lies in the top left hand corner of the graph. The graph shows how controlling the amount of metal in the aperture can allow the user to choose their optimum compromise between antenna size and S21. As the ratio of metal to non-metal decreased, the results tended towards the (empty) aperture point. The results also show that the overall performance can be improved by using finer scales of metallic elements. This was true for both the $10 \mu \mathrm{m}$ dots compared to the $20 \mu \mathrm{m}$ dots and also for the $10 \mu \mathrm{m}$ strips compared to the $20 \mu \mathrm{m}$ strips. To confirm this hypothesis, $40 \mu \mathrm{m}$ dots and strips were considered which further reduced the performance. The figure also shows that the aperture with dots performed better than the aperture with strips for the same scale of object.

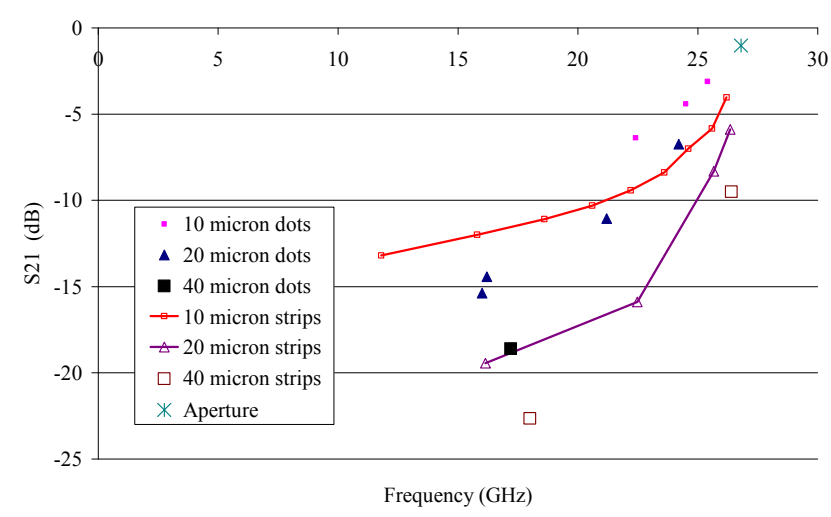

Fig. 6. Comparing the performance of dots and strips in an aperture.
This paper has investigated the potential to use fine scale structures to modify conventional antennas. Our long term goal is to fabricate microwave antennas using nanomaterials. Obviously, this requires a lot of computational memory and processing time and in this paper, larger scale approximations have been used. Note, that these scales are much smaller than the wavelengths considered.

The resonance frequency of dipole and loop radiators have been reduced with the use of additional strips while the bandwidth was increased. The S21 was not significantly effected. The addition of these metallic strips increases the physical size of the antenna but the increase of the radian sphere of the antenna is negligible.

When metal dots and strips were added to an aperture, the external dimensions were unchanged. These additional fine scale metallic objects reduced the resonant frequency, therefore making the antenna electrically larger, however, the S21 was adversely affected. There was a trade off between the frequency and the S21. Simulation results showed that the overall performance of the antenna could be improved by using metallic objects with a smaller scale. This suggests that the use of carefully designed nanomaterial structures could be beneficial in the microwave antenna construction process. Future work will use more powerful computers to extend this work to even smaller scales and will attempt to compare the simulated results to measurements made with samples made using nanomaterials.

\section{REFERENCES}

[1] F. Colombel, X. Castel, M. Himdi, G. Legeay, S. Vigneron, and E. M. Cruz, "Ultrathin metal layer, ITO film and $\mathrm{ITO} / \mathrm{Cu} / \mathrm{ITO}$ multilayer towards transparent antenna," Science, Measurement \& Technology, IET, vol. 3, pp. 229-234, 2009.

[2] W. G. Whittow and Y. Vardaxoglou, "Nanometamaterial Antennas At Microwave Frequencies," presented at Nanometa 2009, Seefeld, Austria, 2009.

[3] W. G. Whittow and Y. Vardaxoglou, "Loop antennas at microwave frequencies using nano-metamaterials," presented at IEEE International Symposium on Antennas \& Propagation and USNC/URSI National Radio Science Meeting Charleston, SC, USA, 2009. W. G. Whittow, Y. Vardaxoglou, C. Toprakcioglu, and N. Spiliopoulos, "Reflection and Transmission Coefficients of Nano-metamaterial Antennas at Microwave Frequencies," presented at Metamaterials 2009, London, UK, 2009.

A. P. Feresidis, G. Apostolopoulos, N. Serfas, and J. C. Vardaxoglou, "Closely coupled metallodielectric electromagnetic band-gap structures formed by double-layer dipole and tripole arrays," Antennas and Propagation, IEEE Transactions on, vol. 52, pp. 1149-1158, 2004. 
Paper published in Loughborough Antennas \& Propagation Conference (LAPC), pp 749-752, 2009

[6] C. Caloz, A. Lai, and T. Itoh, "The challenge of homogenization in metamaterials," New Journal of Physics, vol. 7, pp. 1-14, 2005.

[7] R. Mittra, "Performance enhancement of small antennas using metamaterials; challenges and future directions," presented at 19th International Conference on Applied Electromagnetics and Communications (ICECom 2007), 2007. 